\title{
UMA EXPERIÊNCIA BRASILEIRA DE EDUCAÇÃO INCLUSIVA NO INTERIOR DO ESTADO DO MARANHÃO
}

\author{
Dimas dos Reis RIBEIRO ${ }^{1}$ \\ Dulce Núbia Rodrigues RÊGO ${ }^{2}$ \\ Julyana Cabral ARAÚJO ${ }^{3}$
}

RESUMO: A educação inclusiva visa a integração de educandos com diferenças físicas e mentais no contexto escolar, para que os mesmos se sintam parte do processo de ensino-aprendizagem. Essa prática surgiu com o objetivo de inserir todos os educandos no ensino regular, de tal forma que todos adquiriram noções de uma educação humanística e democrática. Foi como bolsistas do PIBID na Escola José de Anchieta que deparamos com a experiência exitosa de Escola Inclusiva, onde os educandos aprendem a respeitar as diferenças do outro e, ao interagirem na mesma sala de aula, familiarizam-se com as situações cotidianas. Os educandos diferentes da instituição desenvolvem trabalhos com músicas e sua sensibilidade e capacidade de percepção do que acontece ao seu redor deixa-os seguros e independentes, principalmente os educandos com diferenças visuais, que se destacam tocando instrumentos como teclado e violão. A escola dispõe de educadores capacitados em braile e libras e possui uma sala exclusiva com todo o material de que precisam para despertar as aptidões dos educandos diferentes em um momento só deles. É perceptível o talento que eles possuem e desenvolvem na arte e na música. A sua condição de diferente não interfere no seu desenvolvimento que é uma questão trabalhada em sala de aula, de tal forma que os outros educandos passam a interagir de forma natural. Isso mostra o quanto podemos aprender com eles e a partir do ponto de vista do outro tirar verdadeiras lições de vida.

PALAVRAS-CHAVE: Educação. Inclusão. Diferente. Educando. Educador.

\section{Introdução}

Sem sombra de dúvida a Educação inclusiva é um dos grandes desafios da contemporaneidade. Mas se hoje esse desafio é enorme, há alguns anos atrás ele parecia inatingível e intransponível. Para comprovar essa realidade basta olhar no retrovisor da História e resgatar um pouco das ações delineadas nas últimas décadas.

1 Docente no Departamento do Curso de Licenciatura Interdisciplinar em Ciências Humanas e Coordenador bolsista PIBID. UFMA - Universidade Federal do Maranhão. Pinheiro - MA - Brasil. 62500-000 - profdimas@ uol.com.br.

2 Discente do Curso de Licenciatura Interdisciplinar em Ciências Humanas/História e bolsista PIBID. UFMA - Universidade Federal do Maranhão. Pinheiro - MA - Brasil. 65200-000 - dulcerego@bol.com.br.

${ }^{3}$ Discente do Curso de Licenciatura Interdisciplinar em Ciências Humanas/História e bolsista PIBID. UFMA - Universidade Federal do Maranhão. Pinheiro - MA - Brasil. 65200-000 jhully_araujo@hotmail.com. 
Por exemplo, em 1990 na Conferência Mundial de Educação, ocorrida de 5 a 9 de março, em Jomtien, Tailândia (UNESCO, 1990), quando foi aprovado o direito a educação para todos, visando a satisfação das necessidades básicas de aprendizagem. $\mathrm{O}$ Brasil firmou o compromisso de lutar pela educação e isso fica evidente por ocasião da elaboração dos Parâmetros Curriculares Nacionais - PCNs (BRASIL, 1997, p.14),

Em 1990 o Brasil participou da Conferência Mundial de Educação para Todos, em Jomtien, na Tailândia, convocada pela UNESCO, UNICEF, PNUD e Banco Mundial. Dessa conferência, assim como da Declaração de Nova Delhi - assinada pelos nove países em desenvolvimento de maior contingente populacional do mundo -, resultaram posições consensuais na luta pela satisfação das necessidades básicas de aprendizagem para todos, capazes de tornar universal a educação fundamental e de ampliar as oportunidades de aprendizagem para crianças, jovens e adultos.

Ainda em 1991, através da Lei $n^{\circ} 8.213$, de 24 de julho, mais conhecida como Lei de Cotas (BRASIL, 1991), foi fixado cotas percentuais, de acordo com o número de empregados.

Prevê cotas para portadores de deficiência no mercado de trabalho. Dispõe referida lei que as empresas que têm de 100 a 200 empregados devem reservar, obrigatoriamente, $2 \%$ de suas vagas para pessoas com deficiência, que pode ser visual, auditiva, física ou mental. Para as empresas que têm de 201 a 500 empregados, a cota reservada aos portadores de deficiência é de 3\%. Para as que têm de 501 a mil empregados, de $4 \%$. E para as que têm mais de mil, de $5 \%$. (FONSECA, 2012, sem paginação).

A Declaração de Salamanca (UNESCO, 1994) - teve papel singular no planejamento e na implementação de políticas públicas indutoras de ações concretas capazes de garantir os diretos dos diferentes à educação. Tanto que os signatários dessa obra prima, assim pronunciaram:

Nós congregamos todos os governos e demandamos que eles:

- atribuam a mais alta prioridade política e financeira ao aprimoramento de seus sistemas educacionais no sentido de se tornarem aptos a incluírem todas as crianças, independentemente de suas diferenças ou dificuldades individuais;

- adotem o princípio de educação inclusiva em forma de lei ou de política, matriculando todas as crianças em escolas regulares, a menos que existam fortes razões para agir de outra forma;

- desenvolvam projetos de demonstração e encorajem intercâmbios em países que possuam experiências de escolarização inclusiva; 
- estabeleçam mecanismos participatórios e descentralizados para planejamento, revisão e avaliação de provisão educacional para crianças e adultos com necessidades educacionais especiais;

- encorajem e facilitem a participação de pais, comunidades e organizações de pessoas portadoras de deficiências nos processos de planejamento e tomada de decisão concernentes à provisão de serviços para necessidades educacionais especiais;

- invistam maiores esforços em estratégias de identificação e intervenção precoces, bem como nos aspectos vocacionais da educação inclusiva;

- garantam que, no contexto de uma mudança sistêmica, programas de treinamento de professores, tanto em serviço como durante a formação, incluam a provisão de educação especial dentro das escolas inclusivas. (UNESCO, 1994, sem paginação).

A Lei 9394/96, conhecida por Lei de Diretrizes e Bases da Educação Nacional (BRASIL, 1996) reafirmou o compromisso de garantir educação e atendimento especializado na rede regular de ensino, sinalizando com os apoios necessários que fossem capazes de propiciarem, ou de pelo menos manter viva a chama de se construir uma educação verdadeiramente inclusiva.

Com sua implementação no Brasil no ano de 1996, a LDB traz, em sua redação, muito do que se discutiu na elaboração da Declaração de Salamanca (UNESCO, 1994), onde foi assumido o compromisso com a "Educação para todos" e o reconhecimento da educação para crianças, jovens e adultos com necessidades educacionais especiais, no sistema regular de ensino. (HEREDERO, 2011, p.17).

Na tentativa de cumprir suas pactuações, o Ministério da Educação (MEC) publicou em 1997 os Parâmetros Curriculares Nacionais - PCNs (BRASIL, 1997) de $1^{\text {a }}$ a $4^{\text {a }}$ séries, em 1998, os de $5^{\text {a }}$ a $8^{\text {a }}$ séries, e em 1999, os de ensino médio.

No ano 2000, através da Lei $\mathrm{n}^{\circ}$ 10.098, de 19 de dezembro (BRASIL, 2000), foram estabelecidas as normas gerais e critérios básicos para a promoção da acessibilidade das pessoas portadoras de deficiência ou com mobilidade reduzida, além de sinalizar outras providências.

Outro avanço tardio foi a Lei $\mathrm{n}^{\circ} 10.436$ de 24 de abril de 2002 (BRASIL, 2002) que reconheceu como meio legal de comunicação e expressão a Língua Brasileira de Sinais - Libras e outros recursos de expressão a ela associados.

A partir de 2007, um Grupo de Trabalho nomeado pela Portaria $\mathrm{n}^{\circ}$ 555/2007, prorrogada pela Portaria $n^{\circ}$ 948/2007, formulou a Política Nacional de Educação Especial na Perspectiva da Educação Inclusiva (BRASIL, 2007) e que entregue ao Ministro da Educação em 07 de janeiro de 2008. 
No ano de 2008 foi publicado o Decreto $n^{\circ} 6.571$ que dispunha sobre o atendimento educacional especializado, regulamentou o parágrafo único do art. 60 da Lei 9394/96 e acrescentou dispositivo ao decreto ${ }^{\circ}$ 6.253, de 13 de novembro de 2007 (BRASIL, 2008). Todavia esse decreto acabou sendo revogado na sua totalidade em 2011, pelo Decreto n ${ }^{\text {o }}$ 7.611, de 17 de novembro (BRASIL, 2011) e que mais uma vez dispõe sobre a educação especial, o atendimento educacional especializado, além de dar outras providências. Esta inconstância da legislação deve ser analisada de forma mais detalhada, pois afinal de contas, a que interesses esse procedimento atende?

Com todo esse aparato jurídico foram criadas as bases legais para se exigir e implementar politicas públicas que fossem ao encontro das normas aprovadas, mas como bem sabemos, no Brasil há uma distância enorme entre o ideal e o real, sendo que muito do que de fato tornou-se legal ainda não foi implementado de forma suficiente.

Pensamos que incluir o educando no processo de ensino aprendizagem não é só inseri-lo na sala de aula, não é suficiente integrar os educandos diferentes, ou seja, não basta meras adaptações para receber um grupo de educandos diferentes. Isso é fácil de realizar e parece-nos que é exatamente isso que vem ocorrendo na maioria das escolas que se auto intitulam inclusivas.

É preciso reconhecer que cada aluno aprende de forma e com um ritmo próprio. Respeitar a individualidade de todas as pessoas significa dar oportunidades para todos aprenderem os mesmos conteúdos, fazendo as adaptações necessárias do currículo (HEREDERO, 2011, p.27).

O processo de inclusão requer a reestruturação de toda uma cultura e todo um sistema educacional aonde as mudanças vêm ocorrendo de forma modesta. Só assim construiremos um modelo novo de ensino aprendizagem que seja capaz de cuidar de todos os educandos, criando as condições físicas, sociais, políticas e culturais de pleno acesso e participação de todos.

Toda escola deve ser inclusiva, caso contrário, sequer mereceria a nome de escola. Como não estamos no mundo apenas para lamentar o passado, é hora de todos os envolvidos com a vida escolar, incluindo toda a sociedade, fruto e espelho da realidade, através de ações concretas e revestidas de teoria e prática, discutir, propor e realizar as mudanças que desejamos ver em nossas escolas. Afinal, nós é que devemos ser e fazer o que desejamos ver no mundo. As teorias podem comover, mas os exemplos e as ações concretas é que arrastarão homens e mulheres na implantação de escolas inclusivas, de uma 
educação inclusiva e de um mundo novo possível. (RIBEIRO; LEONELLO, 2011, p.125).

A Educação Inclusiva deve ser o espelho de um humanismo renovado e deve superar o clichê do ensino de conteúdos acadêmicos, deve despertar em cada educando diferente, suas potencialidades e aptidões e assim promover o seu desenvolvimento na totalidade, deve cultivar cada competência, cada atitude, cada conhecimento, pois só assim eles serão reconhecidos e incluídos na sociedade, pois afinal não somos todos iguais, mas todos diferentes. Esse é o paradigma histórico da ilustração, que embora tenha cumprido seu papel num dado momento, precisa ser readequado aos novos tempos e desafios da contemporaneidade.

É exatamente por isso que precisamos avançar e superar até mesmo as denominações que já evoluíram ao longo do tempo, tais como:

A denominação utilizada para se referir às pessoas com alguma limitação física, mental ou sensorial assume várias formas ao longo dos anos. Utilizavam-se expressões como "inválidos", "incapazes", "excepcionais" e "pessoas deficientes", até que a Constituição de 1988, por influência do Movimento Internacional de Pessoas com Deficiência, incorporou a expressão "pessoa portadora de deficiência", que se aplica na legislação ordinária. Adota-se, hoje, também, a expressão "pessoas com necessidades especiais" ou "pessoa especial". Todas elas demonstram uma transformação de tratamento que vai da invalidez e incapacidade à tentativa de nominar a característica peculiar da pessoa, sem estigmatizá-la. A expressão "pessoa com necessidades especiais" é um gênero que contém as pessoas com deficiência, mas também acolhe os idosos, as gestantes, enfim, qualquer situação que implique tratamento diferenciado. Igualmente se abandona a expressão "pessoa portadora de deficiência" com uma concordância em nível internacional, visto que as deficiências não se portam, estão com a pessoa ou na pessoa, o que tem sido motivo para que se use, mais recentemente, conforme se fez ao longo de todo este texto, a forma "pessoa com deficiência". (SASSAKI, 2003, p.1236).

Estamos certos de que o processo de inclusão começa no momento em que nos apropriamos das informações relativas às dificuldades de cada educando, de seu código de aprendizagem, do seu contexto social e individual e só depois verificar as condições existentes e se são satisfatórias para conduzi-lo a uma classe comum ou regular.

Dentre o papel da universidade está o de auxiliar na criação de novas formas de estruturação do processo de ensino-aprendizagem, de tal forma que as necessidades dos educandos sejam priorizadas, além de despertar nos educadores e futuros educadores a compreensão do tamanho do desafio, bem como da importância de impulsionar os 
educandos para que possam superar seus limites e desenvolver ao máximo suas potencialidades.

Nesse sentido, Eugenio (2003) ao construir um diálogo com Le Breton (2008), afirma:

\begin{abstract}
A dependência, a precariedade e a fragilidade que denunciariam a evidência incontornável da deficiência devem ser minimizadas embora sua superação definitiva não seja nunca cogitada como possível -, de modo a aproximar ao máximo seus corpos irregulares do corpo que "não choca nem surpreende" previsto como ideal nas etiquetas ocidentais. Uma série de didáticas especiais é acionada a fim de suprir e contornar aquilo que, naquelas crianças, é lido como deficitário: é preciso que deixem de ser "objeto de seu corpo", por que isso é incompatível com a independência e a autonomia que será exigida delas quando se tornarem adultas. (EUGENIO, 2003, p.217).
\end{abstract}

Afinal de contas, o que realmente precisamos para que nossas escolas possam atingir o status de inclusiva?

Para prosseguir nossa discussão precisamos nos reportar à Declaração de Salamanca (UNESCO, 1994, não paginado):

O desafio com que se confronta a escola inclusiva é o de ser capaz de desenvolver uma pedagogia centrada na criança, susceptível de educar com sucesso todas as crianças, incluindo as que apresentam graves incapacidades. O mérito destas escolas não consiste somente no fato de serem capazes de proporcionar uma educação de qualidade a todas as crianças; a sua existência constitui um passo crucial na ajuda da modificação das atitudes discriminatórias e na criação de sociedades acolhedoras e inclusivas.

Pensamos que como ponto de partida devemos conceber ambientes educacionais flexíveis, adotar estratégias educativas alicerçadas em pesquisas e estudos científicos, facilitar o acesso físico dos diferentes a todos os espaços escolares, criar as condições básicas de trabalho para que a equipe técnica possa se dedicar ao máximo aos projetos de inclusão, despertar o desejo de contribuir e cooperar nas múltiplas relações sociais, criar conexões de esclarecimento nas escolas, disponibilizar a infraestrutura de serviços e de atendimento e, sobretudo, firmar parcerias com as famílias dos diferentes. Pois,

[...] no dizer-se da educação especial, família e escola surgem como instâncias concorrentes. $\mathrm{O}$ discurso autorizado desqualifica não apenas o esforço da família em educar suas crianças, mas toda a vida fora da instituição. Ao decretar que crianças cegas ao contrário das "normais", seriam "incapazes de aprender naturalmente" e precisariam de 
didáticas especiais e de atividades destinadas a "educar os sentidos", a escola especializada, em sua intenção equalizadora, legitima sua própria existência, ao mesmo tempo em que nega o papel educativo da família. (EUGENIO, 2003, p.218).

É verdade que nos desafios de se construir o processo de inclusão já demos alguns passos importantes e entre eles podemos destacar que o sucesso na aprendizagem escolar tem influenciado o desenvolvimento cognitivo e afetivo, fato é que os surdos estão conseguindo vencer a barreira da língua, estão obtendo empregos através da lei das cotas, estão obtendo respeito dos colegas e dos professores, prova inequívoca de que

[...] para os surdos e/ou deficientes auditivos a Libras, como primeira língua numa abordagem bilíngue se constitui num instrumento mais importante para seu aprendizado. Trata-se de uma língua espaçovisual que se compõe de estrutura gramatical e regras de uso, tão completa como qualquer outra língua oral. (PIRES; GARÉ, 2013, p.5).

Em muitas escolas brasileiras, mas de modo singular e único no Centro de Ensino José de Anchieta encontramos implementada uma sala de recursos multifuncionais que procura atender todas as demandas da cidade de Pinheiro.

Outras conquistas que podemos destacar são a reserva de vagas em concurso publico para os diferentes, inclusão digital, Curso de Letras com Libras com vagas específicas para os surdos e aumento do número de acadêmicos cegos nas universidades brasileiras.

Já para os educadores que desejam atuar na educação para os diferentes encontramos cursos para formação continuada, pós-graduação em educação especial e seleção para profissionais qualificados em empresas e instituições públicas privadas.

\section{A experiência pinheirense de atendimento educacional especializado}

Ao visitar a sala de atendimento especial da Escola José de Anchieta no turno vespertino acompanhamos com a educadora responsável pelo reforço escolar dos educandos, o desempenho dos mesmos. A sala fica próximo do pátio da escola e para a melhor locomoção dos educandos diferentes, ao saírem da sala se sentem independentes para passear pela escola somente com uso de uma bengala sem necessitar de um guia. A sala de Atendimento Educacional Especializado (AEE) constitui-se numa ferramenta muito importante no âmbito escolar e tem como função facilitar a acessibilidade desses 
educandos no ensino regular, utilizando de diversos recursos pedagógicos, principalmente softwares para transcrição de textos, o que representa uma alternativa à utilização de materiais artesanais usados até então pelos educandos com diferenças visuais.

O objetivo maior para o aluno incluído com a deficiência visual ou a cegueira, deficiente auditivo e /ou surdo é seu acesso e permanência na escola, sendo que a sala de AEE é uma grande parceira para que essa acessibilidade aconteça. Também sua permanência deve ser assegurada por toda equipe escolar e em parceria com a família, que devem estar juntas e sempre cobrando o que por lei é garantido a esse aluno. (PIRES; GARÉ, 2013, p.5).

Os educandos que apresentam dificuldades em algumas disciplinas recorrem às educadoras responsáveis pela AEE, sendo função delas reforçar o que os educandos veem no ensino regular, dessa forma os educandos conseguem acompanhar o processo de ensino-aprendizagem com os demais educandos.

A tecnologia é um recurso presente na vida desses educandos diferentes, enquanto estávamos na sala, observamos que o uso do celular é frequente, o aparelho tem adaptações para uso dos educandos com diferenças visuais, as teclas sonoras facilitam o uso do mesmo, parecem bem familiarizados com o aparelho, até ensinam para a educadora, o que reforça a ideia de que se comparados a eles também temos dificuldades e é exatamente por isso que devemos chama-los de diferentes e não "deficientes" ou "portadores de necessidades especiais", pois em muitas situações de nossas vidas nós que nos consideramos "normais" também enfrentamos dificuldades e necessitamos de maior atenção.

A sala que visitamos e que nos interagimos com eles dispõe de um software que reproduz o texto em Braille, a educadora afirma que essa ferramenta facilitou muito na elaboração das atividades e na execução dos trabalhos, pois deixou de recorrer a métodos que demandava mais tempo, como furar o papel para produzir um texto em alto relevo, semelhante ao que o computador reproduz num curto espaço de tempo.

Esta sala possui ainda diversos instrumentos que facilitam a aprendizagem dos educandos, a utilização de materiais concretos estimula o educando durante as atividades, são usados barbantes, lã, sementes, algodão, tinta e cola em relevo.

\section{O olhar do Educador e do Educando sobre a inclusão nas escolas}


Segundo a educadora L. C, que atua como intérprete da língua de sinais na rede do Estado, na Escola José de Anchieta, e que trabalha na sala de Atendimento Educacional Especializado para atender necessidades e dar suporte aos educandos com diferenças de audição, desenvolvendo oficinas nas salas de ensino regular, sobre como se comunicar através da língua de sinais. Ela relata que a presença de educandos diferentes auditivos na escola é bem aceita pelos demais educandos do ensino regular que se interessam em aprender braile na intenção de se comunicar com os colegas diferentes na turma.

No município de Pinheiro - MA, encontramos educandos diferentes nas escolas Centro de Ensino Agostinho Ramalho Marques, IEP (Instituto Educacional de Pinheiro) e CAIC (Centro de Aprendizagem, Integração de Cursos), estudando em salas regulares, todavia, essas instituições não possuem salas multifuncionais, o que faz com que seus educandos diferentes recorram à sala de atendimento educacional especializado no Centro de Ensino José de Anchieta, visando um melhor desempenho no aprendizado.

Ao entrevistar R.B.C., educanda do Curso Meio Ambiente Integral com Ensino Médio, no IFMA (Instituto Federal do Maranhão), nos relatou sobre sua experiência na condição de diferente visual, segundo ela , "a inclusão se trata quando o aluno cego ou surdo qualquer que seja a deficiência é incluído junto com os alunos regulares, ou seja, o cego vai estudar junto com o aluno vidente, essa se trata da verdadeira inclusão", ela se diz a favor da inclusão, "a gente aprende melhor" e "é uma forma de nos ingressarmos no mercado de trabalho". Em relação ao acompanhamento dos educadores em sala de aula alguns não aceitam de imediato a presença de educandos diferentes pela falta de preparo na área. Já a aceitação por parte dos colegas na sala de aula tem sido ótima, só encontra dificuldades por parte de alguns educadores que não se adaptam na "nova educação que envolve a inclusão".

Tanto educadores quanto educandos problematizam a carência que existe na educação, em lidar com situações escolares que envolvam o uso e ensino do código de linguagem braile, língua de sinais (libras) e atender as necessidades de um educando diferentes. Notamos que o preconceito é maior por parte dos educadores que não aceitam de imediato seus alunos e olham como se fosse um problema a presença deles, ou seja, ao invés de adequarem-se a uma nova educação, optam por negá-la.

\section{Conclusão}


Sabemos que ainda temos inúmeras dificuldades e lutas a serem travadas na efetivação do processo de inclusão e dentre as dificuldades mais imediatas podemos destacar: as pessoas com diferenças estão 'invisíveis' na escola e na sociedade, grande parte dos educandos diferentes não frequentam escolas, parte dos educadores não possuem formação profissional para atenderem aos educandos, a falta de material traduzido em Braille e em Libras para atender as demandas cotidianas, as salas de recursos multifuncionais embora existam são insuficientes e a tão falada lei de cotas encontra barreiras no meio empresarial que alega que as pessoas com diferenças não estão qualificadas e o mais revoltante de tudo, muitos diferentes quando conseguem adentrar no mercado de trabalho são submetidos a subempregos.

Finalmente sugerimos que cada um que esteja concluindo a leitura desse artigo, sejam pais, educadores, acadêmicos, empresários que façam para si próprios a pergunta: Como posso contribuir para que a educação inclusiva e a inclusão social seja uma realidade?

\title{
A BRAZILIAN EXPERIENCE OF INCLUSIVE EDUCATION WITHIN THE STATE OF MARANHÃO
}

\begin{abstract}
Inclusive education aims at the integration of students with physical and mental differences in the school context, so that they feel part of the teaching-learning process. This practice originated with the goal of placing all students in regular education, so that all acquired notions of a humanistic and democratic education. Was as fellows in the School PIBID José de Anchieta are faced with the successful experience of Inclusive School, where students learn to respect the differences of others and to interact in the same classroom to become familiar with everyday situations. Different learners develop the institution works with music and their sensitivity and perception of what is happening around you makes them safe and independent, especially learners with visual differences that stand out playing instruments such as keyboard and guitar. The school has trained educators in Braille and pounds and has a unique room with all the material they need to raise the skills of different students at a time of their own. It is noticeable the talent they possess and develop in art and music. His condition differently does not interfere in its development which is a matter worked into the classroom, so that other students spend interacting naturally. This shows how much we can learn from them and from the point of view of another take real lessons of life.
\end{abstract}

KEYWORDS: Education. Inclusion. Different. Educating. Educator 


\section{REFERÊNCIAS}

BRASIL. Decreto $n^{0} 7.611$, de 17 de novembro de 2011. Dispõe sobre a educação especial, o atendimento educacional especializado e dá outras providências. Casa Civil; Subchefia para Assuntos Jurídicos, Brasília, DF, nov. 2011. Disponível em: <http://www.planalto.gov.br/ccivil_03/_Ato2011-2014/2011/Decreto/D7611.htm>. Acesso em: 15 fev. 2013.

Ministério da Educação. Decreto n 6.571 de 17 de setembro de 2008. Dispõe sobre o atendimento educacional especializado, regulamenta o parágrafo único do art. 60 da Lei $\mathrm{n}^{\circ}$ 9.394, de 20 de dezembro de 1996 e acrescenta dispositivo ao Decreto $\mathrm{n}^{\circ}$ 6.253, de 13 de novembro de 2007. Brasília, DF: MEC/SEESP, 2008.

. Ministério da Educação. Lei de Diretrizes e Bases da Educação Nacional, LDB 9.394, de 20 de dezembro de 1996. Brasília, DF: MEC/SEESP, 1996.

Ministério da Educação. Secretaria de Educação Especial. Lei no 10.098, de 19 de dezembro de 2000. Brasília, DF: MEC/SEESP, 2000.

Ministério da Educação. Secretaria de Educação Especial. Lei no . 10.436, de 24 de abril de 2002. Dispõe sobre a Língua Brasileira de Sinais - LIBRAS e dá outras providências. Brasília, DF: MEC/SEESP, 2002.

. Ministério da Educação. Parâmetros Curriculares Nacionais (Documento Introdutório). Brasília, DF: MEC/SEF, 1997.

Ministério da Educação. Política Nacional de Educação Especial na

perspectiva da educação inclusiva. Documento elaborado pelo Grupo de Trabalho nomeado pela Portaria Ministerial $\mathrm{n}^{\circ} 555$, de 5 de junho de 2007, prorrogada pela Portaria n ${ }^{\circ}$ 948, de 09 de outubro de 2007. Brasília, DF: MEC/SEESP, 2007.

Ministério do Trabalho. Lei no 8.213, de 24 de julho de 1991. Dispõe sobre os Planos de Benefícios da Previdência e dá outras providências a contratação de portadores de necessidades especiais. Brasília, DF: MTE, SIT/DSST, 1991.

EUGENIO, F. De como olhar onde não se vê: ser antropóloga e ser tia em uma escola especializada para crianças cegas. In: VELHO, G.; KUSCHNIR, K. Pesquisas urbanas: desafios do trabalho antropológico. 1.ed. Rio de Janeiro: Jorge Zahar Editor, 2003. p.209-221.

FONSECA, M. P. A. Cotas de contratação: proporção legal de deficientes deve ser razoável. Revista Consultor Jurídico [online], 14 mar. 2012. Disponível em: <http://www.conjur.com.br/2012-mar-14/cota-contratacao-deficientes-obedecerprincipio-razoabilidade>. Acesso em: 28 ago. 2014.

HEREDERO, E. S. A escola inclusiva em perspectiva: bases legais para sua organização. Alterosa: CEPP, 2011.

LE BRETON, D. Anthropologie du corps et modernité. 5.ed. Paris: Presses Universitaires de France, 2008. 
PIRES, A. M.; GARÉ, R. M. R. Libras e braile: um atendimento especializado. Mundo Jovem, Porto Alegre, n.439, p.5, ago. 2013.

RIBEIRO, D. R.; LEONELLO, J. C. A escola inclusiva em perspectiva. Alterosa: CEPP, 2011.

SASSAKI, R. K. Vida independente: história, movimento, liderança, conceito, reabilitação, emprego e terminologia. Reação: Revista Nacional de Reabilitação, [S.1.], ano 14, n.74, p.14-17, mai./jun. 2003.

UNESCO. Declaração de Salamanca e linha de ação sobre necessidades educativas especiais. Brasília: UNESCO, 1994.

UNESCO. Declaração Mundial sobre Educação para Todos: plano de ação para satisfazer as necessidades básicas de aprendizagem. Jomtiem/Tailândia: UNESCO, 1990 